\title{
Substituent Effect in Photochemistry of Carbonyl Compounds: $\alpha$-Halovalerophenones
}

\author{
Sungsu Cho and Bong Ser Park* \\ Deparment of Chenistry, Dongguk University, Seoul 100-7/5, Korea \\ Received September 18, 2003
}

\begin{abstract}
Valerophenones containing a substituent at alpha position to the carbonyl group show the remarkable substituent effects on their photochemical reactions. $\alpha$-Bromovalerophenone gives only the $\mathrm{C}$ - $\mathrm{Br}$ bond cleavage products, but the $\alpha$-chlorovalerophenone follows the classical Norrish/Yang reaction pathway predominantly.
\end{abstract}

Key Words : Substituent effect, Photochemistry, I lalo ketone

Photochemical reactions of alpha-halo ketones have been known for a long time in organic photochemistry.' The usual reaction routes of these ketones involve photoinduced carbon halogen bond cleavage reactions either from singlet or triplet excited states. The efficient cleavage reactions have been used as photoinitiators for polymerization of several vinyl monomers. ${ }^{2}$ The reaction has recently found itself an useful application into a photoremovable protecting group. ${ }^{3}$ If alphathalo ketones contain a hydrogen atom to be abstracted nearby, the carbon halogen bond cleavage reaction can occur from an intermediate of photoinduced hydrogen abstraction reactions as exemplified by photorelease of $\mathrm{HCl}$ from 2,5-dimethylphenacyl chloride. ${ }^{1}$ Most recently Wessig and coworkers. have reported a new type of reaction from irradiation of some butyrophenones containing a good leaving group such as mesyloxy or trifluoroacetoxy group at alphat to the carbonyl (Scheme 1). ${ }^{5}$ These papers did not mention whether halogens as a leaving group had been tested in their studies. It would be very interesting to see which reaction sequence the a-halo substituted ketones will follow among several competing reaction routes. In the course of our studies on the substituent effect in the Yang photocyclization, ${ }^{6}$ we had chances to look into photochemical properties of $\alpha$-halovalerophenones and found an interesting substituent effect ${ }^{7}$ of these ketones. Here we would like to report our results on this system.

$\alpha$-Bromovalerophenone (1) and $\alpha$-chlorovalerophenone<smiles>[X]C(CCC)C(=O)c1ccccc1</smiles>

$\mathrm{X}=$ OMs or OTs

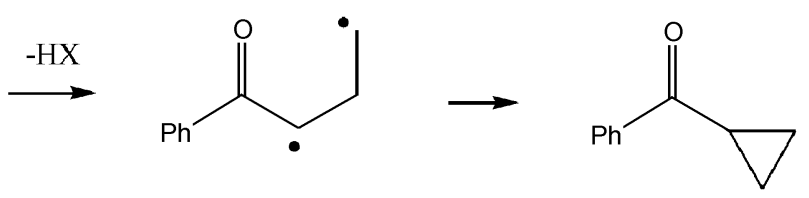

Scheme 1. Photochemical reaction of $\alpha$-substituted buty rophenone.
(2) were prepared by $\alpha$-bromination and chlorination of valerophenone using $\mathrm{CuBr}_{2}$ or $\mathrm{Br}_{2}$ and $\mathrm{SO}_{2} \mathrm{Cl}_{2}$, respectively. Photochemical reactions of both $\mathbf{I}$ and $\mathbf{2}$ were monitored by TIC and turned out to be time dependent. Some of the initially formed products were replaced by other products upon prolonged irradiation. The secondary photoreaction was confirmed later by NMR scale photolysis, vide infra. Fach product was isolated by column chromatography using hexane and ethyl acetate in 10 to 1 ratio as eluents. When the reaction stopped at early stage just before the secondary photoreaction started, two major products from 1 were identified to be valerophenone (VP) and $\beta$-bromovalerophenone (1P) according to usual structural analysis. Compound 2 gave four major products, which were two isomeric 2-chloro-4-methyl-1-phenylcyclobutanols (CB), ${ }^{8}$ $\alpha$-chloroacetophenone (2P) and valerophenone (VP). The starting ketones stayed intact in refluxing benzene for several hours in dark, which confirmed that the process was not thermal but photochemical.<smiles>CCCCC(=O)c1ccccc1</smiles><smiles>CCCCC(=O)c1ccccc1</smiles>

In order to monitor the reaction more closely, a sample in an NMR tube containing 1 or 2 in benzene- $d_{6},(0.02 \mathrm{M})$ was prepared and irradiated under the same condition as above. For 2 hours irradiation of $\mathbf{I}$, the only products detected were VP and IP. As the irradiation continued, the ratio of VP and 1P decreased in compensation for appearance of acetophenone, a photoproduct of VP. Longer irradiation made the reaction mixture more complicated presumably due to formation of more secondary photoproducts not only from $\mathbf{V P}$ but also from 1P. In case of 2 , the reaction mixture 
Table 1. Product Distribution of Photols sis of 1 and 2 in Benzene

\begin{tabular}{ccccc}
\hline Compounds & VP & IP & 2P & CB \\
\hline $\mathbf{I}$ & $35 \%$ & $65 \%$ & & \\
2 & $10 \%$ & & $13 \%$ & $77 \%$ \\
\hline
\end{tabular}

showed formation of four products, whose structures were already identified in large scale photolysis. The secondary photoreaction from VP was also detected upon prolonged irradiation of 2 similarly to the case of 1 . Table 1 summarizes product distribution of photolysis of $\mathbf{1}$ and $\mathbf{2}$.

We also applied the same reaction condition (in dichloromethane containing an acid scavenger, $\mathrm{N}$-methylimidazole) that Wessig used in his study mentioned above, but could not observe formation of the cyclopropyl ketones from 1 or 2 . The reaction was not much different from the results in benzene except that IP was replaced by 1-phenylpent-2-en1-one (PP) in photolysis of 1. Further experiments using other acid scavengers suggested that $\mathbf{I P}$ was the product of $\mathrm{HBr}$ addition to the initially formed $\mathbf{P P}$.

The major difference of photochemical reactions of 1 and $\mathbf{2}$ is that the $\mathrm{C}-\mathrm{Br}$ bond cleavage is the only reaction pathway from 1, but the Norrish/Yang reaction becomes the major reaction from 2. The resulting radical from $\mathrm{C}$-Br cleavage of 1 then abstracts a hydrogen atom from any possible sources in reaction mixture including $\mathrm{HBr}$ to give VP. There were several reports suggesting that ion pairs could be formed from the initially formed radical pairs via electron transfer.' However, the extent that the electron transfer occurs can be considered negligible at least in benzene. The dehydrohalogenation product, $P P$, can also be formed from the radical intermediate as in the case of other $\alpha$-substituted alkanones." In our studies with 1 , however, the dehydrohalogenated product was not observed in benzene. Apparently the $\alpha, \beta$ unsaturated ketone is trapped by $\mathrm{HBr}$ via Michael addition in acidic media to give IP as soon as it is formed.

In case of photolysis of 2 , the $\mathrm{C}-\mathrm{Cl}$ bond cleavage becomes only a minor reaction pathway due to the relatively faster $\gamma$-hydrogen abstraction reaction. The different photochemical behaviors of $\mathbf{1}$ and $\mathbf{2}$ can easily be attributed to bond energy difference of $\mathrm{C}-\mathrm{Br}$ and $\mathrm{C}-\mathrm{Cl}$, which the former (70 kcal/mol) is ca. $14 \mathrm{kcal} / \mathrm{mol}$ weaker than the latter $(84$ $\mathrm{kcal} / \mathrm{mol}){ }^{10}$ Considering that triplet excited state energy is ca. $70 \mathrm{kcal} / \mathrm{mol}$ for both $\alpha$-bromoacetophenone and $\alpha$ chloroacetophenone, ${ }^{12}$ the explanation based on the bond energies does not seem unreasonable. 'The better explanation can, however, be applied here with known kinetic data. Scaiano $t$ al. have studied photoinduced $\mathrm{C}-\mathrm{X}$ cleavage reactions of $\alpha$-bromoacetophenone and $\alpha$-chloroacetophenone by laser flash photolysis and reported that the cleavage rate of the former is over $1 \times 10^{10} \mathrm{~s}^{-3}$ while that of the latter is ca. $3 \times 10^{6} \mathrm{~s}^{-1}$.1] ' Jhis is consistent with our results of $\mathbf{I}$ and 2 . In case of $\mathrm{I}$, the $\mathrm{C}-\mathrm{Br}$ bond cleavage occurs very fast with a rate which $\gamma$ hydrogen abstraction cannot compete. Typical rate constant of $\gamma$-hydrogen abstraction $\left(k_{11}\right)$ of $\alpha$-substituted valerophenone is in the order of $10^{8} \mathrm{~s}^{-1} .^{12}$ In case of 2 , the $\gamma$-hydrogen abstraction reaction occurs much faster than the $\mathrm{C}-\mathrm{Cl}$ bond cleavage, so the former reaction prevails. From our results, the rate constant of $\mathrm{C}-\mathrm{Cl}$ bond cleavage of 2 can be estimated to be ca. $3 \times 10^{7} \mathrm{M}^{-1}$, assuming that $k_{11}$ of 2 is not much different from that of $\alpha$-fluorovalerophenone.

As mentioned above, photolysis of $\mathbf{1}$ and $\mathbf{2}$ did not give the cyclopropyl ketones that Wessig et al. found from several $\alpha$ substituted ketones. They reported that ketones bearing a good leaving group such as sulfonate or nitrate at alpha position to the carbonyl group abstracted a $\gamma$ hydrogen with a rate of $3 \times 10^{8} \mathrm{~s}^{-1}$ and formation of the cyclopropyl ketones from the resulting biradical intermediate occurred with a rate of over $4 \times 10^{7} \mathrm{~s}^{-1}$. Thus the kinetic data can explain why the $\mathrm{C}$ - $\mathrm{Br}$ cleavage reaction of 1 becomes predominant. The reason why the cyclopropyl ketone is missing in photolysis of 2, however, is still puzzling. Wessig has mentioned the involvement of intramolecular $\mathrm{H}$-bonded biradical intermediate shown below (BR1 and BR2) in their reactions. Even though it may explain the different reactivities between the sulfonate ester and the chloride, the more convincing evidences still await further experiments.

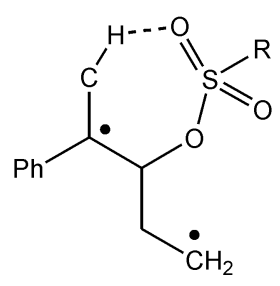

BR1

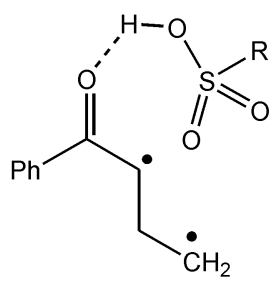

BR2
In summary, valerophenones containing a substituent at alpha position to the carbonyl group showed the remarkable substituent effects on their photochemical reactions. The $\alpha$ bromo ketone, 1 , gives only the $\mathrm{C}-\mathrm{Br}$ bond cleavage products. but the $\alpha$-chloro ketone, 2, follows the classical Norrish Yang reaction pathway predominantly. These behaviors are in a marked contrast with those of ketones bearing other substituents such as $\mathrm{O}$-sulfonyl and $\mathrm{O}$-nitro. Currently other ketones with these substituents are being tested in our laboratory in order to obtain the better idea of the interesting substituent effect.

\section{Experimental Section}

Synthesis of 1: A $250 \mathrm{~mL}$ round bottomed flask was charged with copper(II) bromide (2.75 g. $12.3 \mathrm{mmol})$, valerophenone $(1.00 \mathrm{~g}, 6.2 \mathrm{mmol})$, chloroform $(10 \mathrm{~mL})$ and ethyl acetate $(100 \mathrm{~mL})$ under argon atmosphere and the reaction mixture was refluxed for 48 hours. Distilled water $(20 \mathrm{~mL})$ was added to the solution and insoluble solids were filtered through Buchner funnel. The filtered solution was extracted with ethyl acetate and washed with brine. The combined organic layer was dried using anhydrous $\mathrm{MgSO}_{+}$ and concentrated at reduced pressure. 'The crude product was purified by column chromatography using dichloromethane and $n$-hexane in 2 to 1 to give $1.37 \mathrm{~g}$ of $\alpha$-bromovalero- 
phenone ( $92 \%$ yield).

Spectroscopic properties of $1:{ }^{1} \mathrm{H}$ NMR $\left(\mathrm{CDCl}_{\hat{3}} .200\right.$ MHz): $\delta 8.02(\mathrm{~m} .2 \mathrm{H}), 7.53(\mathrm{~m}, 3 \mathrm{H}) .5 .15$ (dd, $1 \mathrm{H}, J=7.1$. $7.0 \mathrm{~Hz}) .2 .15(\mathrm{~m} .2 \mathrm{H}), 1.5 \mathrm{l}(\mathrm{m} .2 \mathrm{H}) .0 .98(\mathrm{t} .3 \mathrm{H} . J=7.0 \mathrm{~Hz}$ ). ${ }^{13} \mathrm{C} \mathrm{NMR}\left(\mathrm{CDCl}_{3}, 50 \mathrm{MHz}\right): \delta$ 193.4. 134.6. 133.8. 129.0 . $128.9,47.1 .35 .5,20.9,13.7$. IR (neat): $1688(\mathrm{C}=\mathrm{O}) \mathrm{cm}^{-1}$, EI mass: $240\left(\mathrm{M}^{+}\right)$.

Synthesis of 2: Sulfuryl chloride $(8.32 \mathrm{~g} .61 .6 \mathrm{mmol})$ and $p$-toluenesulfonic acid $(0.10 \mathrm{~g})$ were added into $250 \mathrm{~mL}$ round bottomed flask containing valerophenone $(1.00$ g. 6.2 inmol) in dichloromethane. The reaction misture was refluxed for 12 hours. Distilled water $(20 \mathrm{~mL})$ was added and the organic layer was extracted with dichlromethane. After washing with brine. the organic layer was dried using anhydrous $\mathrm{MgSO}_{4}$ and concentrated at reduced pressure. The crude product was purified by colunun chromatography using dichloromethane and $n$-hexane in 2 to 1 to give $1.53 \mathrm{~g}$ of $\alpha$-chlorovalerophenone ( $79 \%$ yield).

Spectroscopic properties of $\dot{2}_{2}{ }^{1} \mathrm{H}$ NMR $\left(\mathrm{CDCl}_{\hat{j}} .200\right.$ MHz): $\delta 8.01(\mathrm{~m} .2 \mathrm{H}), 7.55(\mathrm{~m}, 3 \mathrm{H}) .5 .13(\mathrm{dd}, 1 \mathrm{H}, J=8.0$. $5.8 \mathrm{~Hz}) .2 .03(\mathrm{~m}, 2 \mathrm{H}) .1 .53(\mathrm{~m}, 2 \mathrm{H}) .0 .98(\mathrm{t} .3 \mathrm{H}, J=7.3 \mathrm{~Hz}$ ). ${ }^{13} \mathrm{C} \mathrm{NMR}\left(\mathrm{CDCl}_{3 .} .50 \mathrm{MHz}\right): \delta$ 193.8. 134.7, 133.8. 129.0. 128.9. 57.7. 35.7, 19.7. 13.7. IR (neat): $1693(\mathrm{C}=\mathrm{O}) \mathrm{cm}^{-1} \mathrm{EI}$ mass: $196\left(\mathrm{M}^{+}\right)$.

Photolysis: The starting ketones in benzene (typically $0.01-0.02 \mathrm{M})$ were irradiated in an immersion well with argon bubbling using Pyrex (or Uranium) filtered light of a $450 \mathrm{~W}$ Hanovia medium pressure mercury arc lamp. The reaction misture was concentrated at reduced pressure and the resulting crude product nixture was separated by colunn chromatography using $n$-hexane and ethyl acetate in 7 to $\mathrm{l}$.

For NMR scale photolysis, an NMR tube containing ketones in benzene- $\mathrm{d}_{6}$ was degassed and irradiated by attaching it to the side of an immersion well using Pyrex (or Uranium) filtered light of a $450 \mathrm{~W}$ Hanovia medium pressure mercury arc lamp. To control reaction temperature the sample was immersed in an temperature control bath during the irradiation.

Spectroscopic properties of $1 \mathrm{P}:{ }^{1} \mathrm{H}$ NMR $\left(\mathrm{CDCl}_{3 .} .200\right.$ MHz) $\delta 7.97$ (d. $2 \mathrm{H} . J=7.5 \mathrm{~Hz}$ ). 7.53 (m. $3 \mathrm{H}$ ). $4.58(\mathrm{~m} . \mathrm{lH}$ ). $3.74,3.42$ (doublets of $\mathrm{AB}$ quartets. $2 \mathrm{H} . J=17.2 .7 .2 \mathrm{~Hz}$ ). 1.97 (m. $2 \mathrm{H}$ ). $1.1 \mathrm{l}(\mathrm{t}, 3 \mathrm{H}, J=7.2 \mathrm{~Hz}) .{ }^{13} \mathrm{C}$ NMR $\left(\mathrm{CDCl}_{3} .50\right.$ MHz) $\delta$ 196.9. 136.7, 133.5. 128.8. 128.2, 51.8, 47.4. 32.2 .
12.2. IR (neat): $1686(\mathrm{C}=\mathrm{O}) \mathrm{cm}^{-1} \mathrm{EI}$ mass: $240\left(\mathrm{M}^{-}\right)$.

\section{References and Notes}

1. (a) Sonałane. H. R.: Bellur. N. S.: Nazeruddin, G. M Tetrahedon 1995. 51, 11281. (b) Izawa, Y; Watoh. Y: Tomioka. H. Chem. Lett. 1984. 33. (c) Izawa. Y.: Katsuhiro, I.: Tomioka, H. Bull. Chem. Soc. Jpn. 1983. 56. 1490. (d) Purchit. P. C.: Sonawane. H. R. Tetrahedron 1981. 37. 873. (e) Anderson. T. C.: Reese. C. B. Tatrahedron Lett 1962. 1. 1 .

2. Rabek. J. F. Hechanisnts of Photophnsical Processes and Photochemical Reactions in Pohnters. J. Wiley and Sons: Chichester. 1987 and references therein.

3. (a) Pelliccioli. A. P.: Klan. P.: Zabadal. M.: Wirz. I. I. Am. Chem. Soc. 2001. 123.7931. (b) Rajesh. C. S.: Givens. R. S.: Wilz. I. J Am. Chem. Soc. 2000. 122. 611. (c) Conrad. P. G.: Givens. R. S.: Hellrung. B.: Rajesh. C. S.; Ramseier, M.: Wirz, J. J. Am. Chent Soc. $2000,122,9346$.

4. (a) Bergmark. W. R; Banes, C. Clark. J: Paprian, S: Marytowski. S. J. Ong. Chom. 1985. 50. 5612. (2) Pelliccioli. A. P.: Klan. P.: Zabadal. M.: Wirz. T. J. Am. Chem. Soc. 2001. 223. 7931.

5. (a) Wessig. P; Muhling O. Angew. Chent. Int. Ed. 2001. 40. 1064 (b) Wessig, P. Muhling, O. Helv Chim . Acta 2003.86.865.

6. (a) Chang. D. J.: Nahm, K. Park, B. S. Terahedhon Lett. 2002, +3. 4249. (b) Kim. H.: Kim. T. G.: Hahn. J.: Jang. D. -J.: Chang. D. T.: Park. B. S. J. Plys. Chem at 2001. 105(14). 3555. (c) Chang. D. J.: Park. B. S. Tetrahedron Lett 2001. 42. 711 . (d) Noh. T: Choi. K. Kwon, H.; Chang, D. J.; Park. B. S. Bull Korean Chem. Soc. 1999. 20, 539. (e) Kim. T. Y.: Ko, E. S.; Park. B. S.: Yoon. H. J.: Chae. W. K. Bull. Korem Chem. Soc. 1997, 18. 439. (f) Kim, T. Y. Park. B. S. Bull. Korean Chem. Soc. 1997. 18. 141. (g) Lee. J. W.: Lee. K. H.: Ko. E. S.: Park. B. S.: Chae. W. K. Bull. Konam Chem. Soc. 1995. 16.470.

7. (a) Park. Y.-T.; Song, M.-G.: Kim, M.S.; Kwon. J.-H. Bull Korean Chem. Soc. 2002, 23, 12088. (b) Shin. E. J.; Lee, S. H. Bull. Korean Chem. Soc. 2002. 23. 1309 .

8. The two isomeric 2-chloro-4-methyl-1-phenylcyclobutanols could not be separated even after several column chromatography. The structural identification and assignment were made by decoupling experiments and by comparing its ${ }^{1} \mathrm{H}$ NMR spectra with those of 4-methyl-1-phenylcyclobutanol and other known analogues.

9. Ji, S.-J.: Takahashi, E.; Takahashi. T. T.: Horiuchi. C. A. Tetrohedron Lett 1999. 40.9263 .

10. Lowly. T. H.: Richaedson. K. H. Mechanism and Theory in Organic Chemisny. 3rd ed. Harper and Row. Publishers: New York. U.S.A.. 1987; p 161.

11. MoGimpsey, W. G.; Scaiano, J. C. Cam. J. Chent 1988, 66, 1474.

12. (a) Wagner. P. J.: Park, B. S. Org. Photochem. 1991, 11. 227. (b) Wagner. P. J.: Thomas. M. J. Puchalsti. A. E. J. Am. Chem. Soc. 1986. 108,7739 . 